\title{
Descripción de la segunda especie del género Euacanthe (Scortechiniaceae, Coronophorales), de áreas verdes urbanas y periurbanas de Xalapa, México Second described species of the genus Euacanthe (Scortechiniaceae, Coronophorales), of urban and peri-urban green areas of Xalapa, Mexico
} Acta Botanica Mexicana

\author{
Santiago Chacón Zapata’ @, Dolores González',2 @]
}

\section{Resumen}

Antecedentes y Objetivos: Poco se conoce sobre los hongos ascomicetos de áreas verdes urbanas de México. No obstante, se encontraron algunos registros de especies colectadas en parques y jardines de la ciudad de Xalapa, Veracruz, México, en donde se descubrió una especie nueva del género Euacanthe considerado, hasta ahora, monotípico. Este trabajo tiene como objetivo describir una nueva especie de este género poco común de Coronophorales con base en estudios morfológicos y moleculares.

Métodos: Se realizaron varias exploraciones para la recolecta de material fresco a distintos sitios de áreas verdes urbanas de Xalapa, entre 2013 y 2015, para su revisión junto con el material previamente depositado en XAL. Se realizó un estudio morfológico macro y microscópico de los ejemplares y análisis filogenéticos con secuencias de los genes $28 \mathrm{~S}$, rpb2 y tef1 $\alpha$ junto con las disponibles en GenBank del orden Coronophorales.

Resultados clave: Se describe una especie nueva de ascomiceto saprobio: Euacanthe renispora (Scortechiniaceae, Coronophorales). Esta especie presenta esporas reniformes y cuerpos quellkörper. Se muestran dibujos y fotografías de las estructuras microscópicas más relevantes y la posición filogenética de la nueva especie dentro del orden.

Conclusiones: La descripción de Euacanthe renispora, procedente de áreas verdes urbanas y periurbanas de Xalapa, revela lo poco que se conoce sobre la diversidad fúngica de estos sitios y localidades similares que pudieran existir en otras ciudades del país. Esta nueva especie corresponde al primer Euacanthe registrado para México y la segunda especie para el género.

Palabras clave: Ascomycota, filogenia molecular, hongos urbanos y periurbanos, nuevo taxón.

\section{Abstract}

Background and Aims: Little is known about ascomycete fungi from urban green areas in Mexico. However, some records of species collected in parks and gardens of the city of Xalapa, Veracruz, Mexico, were found, from where a new species of the genus Euacanthe, considered until now monotypic, was discovered. This work aims to describe a new species of this uncommon genus of Coronophorales based on morphological and molecular studies. Methods: Several explorations were carried out to collect fresh material at different sites in the urban green areas of Xalapa between 2013 and 2015 for its revision, besides the material previously deposited in XAL. A macro- and microscopic morphological study of the specimens was performed, together with molecular analyses using sequences of the $28 \mathrm{~S}, r p b 2$, and tef1 $\alpha$ genes and available sequences in GenBank of the Coronophorales.

Key results: The description of a new species of saprobic ascomycetes is presented: Euacanthe renispora (Scortechiniaceae, Coronophorales). This species has reniform spores and the presence of quellkörper bodies. Drawings and photographs of the most relevant microscopic structures and the phylogenetic position of the new species within the order are presented.

Conclusions: The description of Euacanthe renispora from urban and peri-urban green areas of Xalapa reveals that very little is known about the fungal diversity from these sites and similar localities that could exist in other cities of the country. This new species is the first Euacanthe recorded from Mexico and the second species for the genus.

Key words: Ascomycota, molecular phylogeny, new taxon, urban and peri-urban fungi.

${ }^{1}$ Instituto de Ecología, A.C., Red de Biodiversidad y Recibido: 10 de diciembre de 2020.

Sistemática, Carretera antigua a Coatepec No. 351, Col. Revisado: 18 de febrero de 2021.

El Haya, 91073 Xalapa, Veracruz, México.

${ }^{2}$ Autor para la correspondencia: dolores.gonzalez@ inecol.mx
Aceptado por Marie-Stéphanie Samain: 20 de marzo

de 2021.

Publicado Primero en línea: 7 de abril de 2021.

Publicado: Acta Botanica Mexicana 128(2021).
Citar como: Chacón Zapata, S. y D. González. 2021. Descripción de la segunda especie del género Euacanthe (Scortechiniaceae, Coronophorales), de áreas verdes urbanas y periurbanas de Xalapa, México. Acta Botanica Mexicana 128: e1835. DOI: https:// doi.org/10.21829/abm128.2021.1835 c) (7) (5) Este es un artículo de acceso abierto bajo la licencia Creative Commons 4.0 Atribución-No Comercial (CC BY-NC 4.0 Internacional). 


\section{Introducción}

Xalapa, Veracruz, es una de las pocas ciudades de México que cuentan con un número significativo de áreas verdes urbanas y periurbanas (parques y jardines) dentro de la ciudad y sus alrededores (Capitanachi et al., 2004). El paisaje está formado por lomeríos e incluye parches de áreas perturbadas y preservadas de bosque de niebla mejor conocido como bosque mesófilo de montaña (Chacón et al., 1995). De acuerdo con Capitanachi et al. (2004), existen 112 áreas verdes en Xalapa. Sin embargo, solo siete de ellas (Santuario del Bosque de Niebla (SBN); Jardín Botánico Francisco Javier Clavijero (JBFJC); Lomas de San Roque; Parque Ecológico Cerro Macuiltépetl; Parque Natura; Parque Los Berros y Parque Los Tecajetes) se han mencionado en estudios taxonómicos sobre hongos, o sobre biodiversidad (Chacón et al., 1995; 2014; 2018(2019); Heredia et al., 2000; Chacón-Zapata y Tapia-Padilla, 2013; Bandala y Montoya, 2014; MacGregor-Fors et al., 2016; Tapia et al., 2017; Chacón-Zapata, 2019; Chacón y González, 2019). Referente a los hongos ascomicetos, hasta ahora solo se han citado algunos géneros y especies de Xylariales y Pezizales procedentes del SBN y del JBFJC (Chacón et al., 1995; Medel y Calonge, 2004; Medel et al., 2008; Chacón y González, 2019), por lo que el conocimiento sobre este grupo de hongos, incluyendo aquellos del orden Coronophorales, es todavía muy escaso.

El género Euacanthe Theiss. fue propuesto por Theissen (1917, en Subramanian y Sekar, 1990) para acomodar a Meliolopsis usambarensis Rehm. Sin embargo, Nannfeldt (1975) encontró que Sphaeria foveolata Berk. \& M.A. Curtis era un nombre ya existente para este hongo, por lo que lo transfirió a Acanthonitschkea Speg., como Acanthonitschkea foveolata (Berk. \& M.A. Curtis ex Berk.) Nannf. Posteriormente, Subramanian y Sekar (1990) reconocieron a Euacanthe y realizaron la combinación de A. foveolata, transfiriéndola a Euacanthe foveolata (Berk. \& M.A. Curtis ex Berk.) Subram. \& Sekar. No obstante, en la base de datos de Mycobank (Robert et al., 2005), se mantiene el registro de dos especies: E. usambarensis (Rhem) Theiss y E. foveolata, ambas adscritas a la familia Nitschkiaceae del orden Sordariales. En Index Fungorum (2021), Euacanthe es tratado como monotípico ( $E$. usambarensis), toda vez que E. foveolata es considerada sinónimo de Acanthonitschkea foveolata. Sin embargo, Euacanthe se distingue de Acanthonitschkea por la presencia de cuerpos de expansión llamados quellkörper. Los cuerpos de quellkörper sirven para romper la pared del pseudotecio, propiciando con ello la apertura del ascoma y en consecuencia la liberación de las esporas (Mugambi y Huhndorf, 2010). La posición sistemática de Euacanthe ha sido tratada con caracteres morfológicos y moleculares. Estos últimos avalan sus cambios nomenclaturales y lo ubican actualmente como un género monotípico adscrito a la familia Scortechiniaceae, del orden Coronophorales (Huhndorf et al., 2004; Kirk et al., 2008; Mugambi y Huhndorf, 2010; Maharachchikumbura et al., 2016; Hyde et al., 2020), resolución que es aceptada en la presente contribución. Euacanthe se caracteriza por los ascomas superficiales colapsados, subículo presente con abundantes setas, ascas octosporadas y la presencia de cuerpos quellkörper (Subramanian y Sekar, 1990; Mugambi y Huhndorf, 2010).

Por otro lado, a pesar de la gran diversidad fúngica que ostenta México, el género Euacanthe no había sido registrado para el país, aunque sí otras especies adscritas a los Coronophorales, como Nitschkia grevillei (Rehm) Nannf. (Medel y Chacón, 1988), Acanthonitschkea argentinensis Speg. (San Martín González y Lavín, 1997), Calyculosphaeria calyculus (Mont.) Fitzp., C. tetraspora (Nannf.) F. San Martín, Scortechinia acanthostroma (Mont.) Sacc. \& Berl., Spinulosphaeria thaxteri (Pat.) Sivan., Bertia didyma (Speg.) Mugambi \& Huhndorf (como Thaxteria didyma (Speg.) Sacc.) y Fracchiaea heterogenea Sacc. (San Martín González, 1996; Raymundo et al., 2014). En esta investigación se describe una nueva especie de Euacanthe, con lo cual se eleva a dos, el número de especies descritas para este género de Coronophorales.

\section{Materiales y Métodos}

\section{Recolección de ejemplares}

El presente trabajo se basó en la revisión y estudio de ejemplares previamente depositados en la colección de hongos del herbario XAL, del Instituto de Ecología, A.C. (INECOL), $y$ en material fresco recolectado entre 2013 y 2015. Las muestras estudiadas (G. Guzmán 24105 (XAL), 32780 (XAL), S. Chacón 4935 (XAL) y Tapia 2797 (XAL)) proceden de cuatro áreas verdes urbanas y periurbanas localizadas en la ciu- 
dad de Xalapa (Parque Ecológico "Cerro Macuiltépetl", "Jardín de casa particular", "Santuario del Bosque de Niebla" y "Zoncuantla") (Fig. 1). Cada sitio se separa de los demás por una distancia entre 0.5 y $5 \mathrm{~km}$, la altitud entre sitios varía de 1300 a 1586 m s.n.m., la precipitación promedio anual es de 1590 mm (Zolá, 1987). El clima es templado húmedo con lluvias la mayor parte del año; la temperatura promedio anual varía de 16 a $18^{\circ} \mathrm{C}$. Algunos sitios incluyen parches conservados de bosque mesófilo de montaña con presencia de especies vegetales con afinidad templada de géneros como Carpinus L., Clethra L., Platanus L. y Quercus L., además de otros árboles y arbustos del sotobosque con afinidad tropical (Muñiz-Castro et al., 2006, Toledo-Aceves et al., 2014).

\section{Estudio morfológico}

Para la descripción de los ascomas se utilizó un microscopio estereoscópico (Zeiss Stemi DRC, Jena, Alemania). Además, se hicieron cortes a navaja de los ascomas y se colocaron en agua destilada e hidróxido de potasio $(\mathrm{KOH})$ al $3 \%$ para su observación en el microscopio de campo claro (Zeiss 470801, Jena, Alemania), donde se tomaron medidas de ascas, ascosporas, setas, hifas del subículo, espesor del peridio y cuerpos quellkörper. Para una descripción más

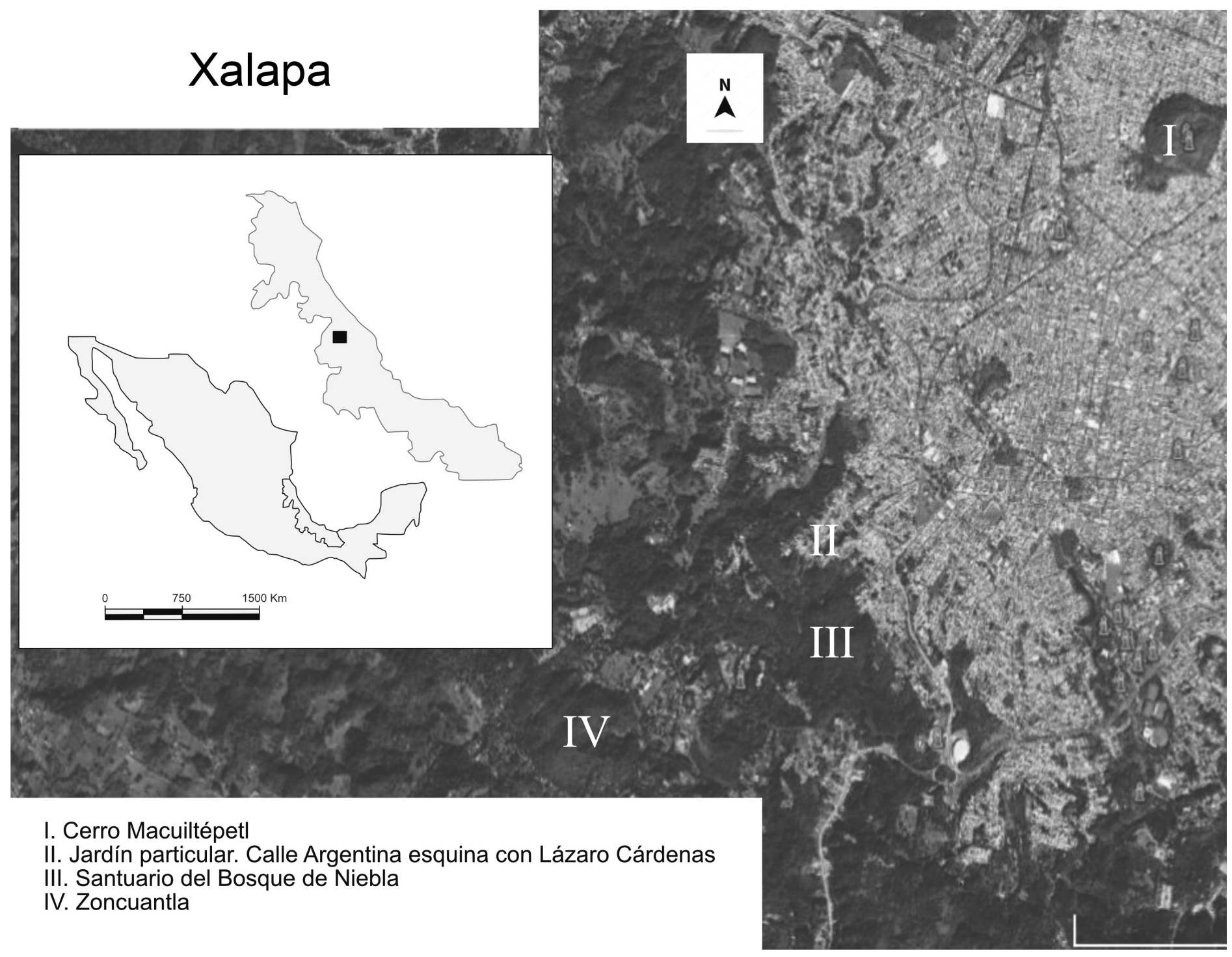

Figura 1: Vista parcial de Xalapa, Veracruz, México (en gris) y áreas vecinas, mostrando los sitios de recolección de ejemplares (https://earth.google. com/web/, editado y modificado por Manuel Escamilla). 
detallada se realizaron dibujos y se tomaron fotografías de algunas de las estructuras microscópicas más relevantes. Los ejemplares estudiados están depositados en la colección de hongos del herbario XAL.

\section{Extracción de ADN, amplificación y secuencia- ción}

Para la extracción de ADN, se separó un ascoma de los cuatro ejemplares usados para este estudio (G. Guzmán 24105 (XAL), 32780 (XAL), S. Chacón 4935 (XAL) y Tapia 2797 (XAL)). Cada ascoma se lavó repetidas veces con agua destilada antes de macerarse en un disruptor tisular (Tissuelyser II, Qiagen, Valencia, EUA) por 45 segundos. La extracción de ADN se llevó a cabo utilizando el Kit NucleoSpin Plant II (Macherey-Nagel, Bethlehem, PA, EUA), siguiendo el protocolo del fabricante.

Se amplificaron tres regiones de genes nucleares, el $28 S$ (codifica la subunidad grande del DNA ribosomal), el rpb2 (codifica la segunda subunidad grande de la RNA polimerasa II) y el tef1 $\alpha$ (codifica el factor de elongación 1 alfa). Las reacciones de amplificación se realizaron en un termociclador Eppendorf (Mastercycler proS, Hamburgo, Alemania). La mezcla de reacción consistió en un volumen total de $25 \mu \mathrm{l}$ que contenía entre 25-50 ng de ADN, $5 \mu \mathrm{l}$ de buffer $5 \times, 0.2 \mathrm{mM}$ dNTPs, $1.6 \mu \mathrm{M}$ de ambos cebadores (directo e inverso), $2 \mathrm{mM} \mathrm{MgCl}, 0.2 \mathrm{U}$ de polimerasa Go Taq flexi DNA (Promega, Madison, Wisconsin, EUA) y agua destilada. Las condiciones de la amplificación se describen en el Cuadro 1.

Los productos de amplificación se corrieron en un gel de agarosa al $1.5 \%$ y se cortaron para su purificación con el kit GenElute Gel (Sigma-Aldrich, St. Louis, Missouri, EUA). La secuenciación se realizó con el kit ABI PRISM BigDye Terminator v. 3.1 (Applied Biosystems, Foster City, EUA), de acuerdo con las instrucciones del proveedor. Los productos de PCR se purificaron con isopropanol y se procesaron con el equipo $A B I 310$ Genetic Analyzer (Applied Biosystems, Foster City, California, EUA) del INECOL.

Las secuencias de las tres regiones génicas se editaron con el programa BioEdit v. 7.1.3.0 (Hall, 1999) y se compararon en la base de datos de nucleótidos (nr/nt) de GenBank (https://blast.ncbi.nlm.nih.gov/Blast.cgi) con el algoritmo blastn para conocer los taxa con afinidad en sus secuencias.

Después de identificar los taxones con mayor identidad, se descargaron todas las secuencias disponibles en GenBank del orden Coronophorales. Se ensamblaron tres matrices, una con secuencias del 28S; otra con las del rpb2 y la tercera con secuencias del tef $1 \alpha$. Estas matrices contenían secuencias principalmente de estudios realizados por Subramanian y Sekar (1990), Huhndorf et al. (2004) y Mugambi y Huhndorf (2010) dentro del orden Coronophorales (Cuadro 2). La alineación se realizó con Clustal W, dentro del programa BioEdit v. 7.1.3.0 (Hall, 1999).

Cuadro 1: Oligonucleótidos usados y condiciones de las reacciones de PCR que se usaron para amplificar Euacanthe renispora S. Chacón.

\begin{tabular}{|c|c|c|c|c|}
\hline Gen & Nombre & Referencia & Secuencia $\left(5^{\prime}-3^{\prime}\right)$ & $\begin{array}{c}\text { Hibridación y extensión } \\
\text { de la reacción }\end{array}$ \\
\hline & LROR & & ACCCGCTGAACTTAAGC & $51^{\circ} \mathrm{C}, 45 \mathrm{~s}$ \\
\hline \multirow[t]{3}{*}{$28 \mathrm{~S}$} & & Vilgalys y Hester, 1990 & & \\
\hline & LR5 & & TCCTGAGGGAAACTTCG & $72{ }^{\circ} \mathrm{C}, 1 \mathrm{~min}$ \\
\hline & RPB2-980F & Reeb et al., 2004 & TGYCCIGCIGARACICCHGARGG & $57^{\circ} \mathrm{C}, 1 \mathrm{~min}$ \\
\hline \multicolumn{5}{|l|}{$r p b 2$} \\
\hline & fRPB2-7cR & Liu et al., 1999 & CCCATRGCTTGYTTRCCCAT & $72{ }^{\circ} \mathrm{C}, 2 \mathrm{~min}$ \\
\hline & $983 \mathrm{~F}$ & Sung et al., 2007 & GCYCCYGGHCAYCGTGAYTTYAT & $60^{\circ} \mathrm{C}, 30 \mathrm{~s}$ \\
\hline & EF1-GY-R & Diseñado por el autor (DG) & TCRACGGAYTTGACTTCAGTGGT & $72{ }^{\circ} \mathrm{C}, 1 \mathrm{~min}$ \\
\hline
\end{tabular}


Cuadro 2: Especies utilizadas en el análisis filogenético y número de acceso en GenBank. En negritas los números de acceso de Euacanthe renispora S. Chacón. ${ }^{1 / C B S}$ : Central Bureau of Fungal Cultures; CPC: Culture collection of Pedro Crous; GKM: George K. Mugambi; IFRD: International Fungal Research \& Development Centre; FMR: Facultat de Medicina i Ciències de la Salut; SMH: Sabine M. Huhndorf; ANM: Andrew N. Miller; F: Field Museum of Natural History; EA: National Museum of Kenya; MO: Missouri Botanical Garden.

\begin{tabular}{|c|c|c|c|}
\hline \multirow{2}{*}{ Especie $^{1 /(\text { origen) }}$} & \multicolumn{3}{|c|}{ Números de acceso de GenBank } \\
\hline & $28 S$ & $r p b 2$ & tef1 $\alpha$ \\
\hline Acanthonitschkea argentinensis voucher SMH1395 & AY695259 & FJ968943 & FJ969042 \\
\hline Acanthonitschkea tristis strain SMH4723 & FJ968949 & & FJ969043 \\
\hline Bahusakala longispora CBS 54484 from TYPE material & NG064138 & & \\
\hline Bertia didyma strain SMH4256 & FJ968950 & & \\
\hline Bertia didyma strain SMH4719 & FJ968958 & & \\
\hline Bertia gigantospora strain GKM1136 & & & FJ969008 \\
\hline Bertia moriformis & & AY780151 & \\
\hline Bertia moriformis strain SMH5169 & FJ968951 & & \\
\hline Bertia moriformis voucher SMH3344 & AY695261 & & \\
\hline Bertia moriformis voucher SMH4320 & AY695260 & & \\
\hline Bertia multiseptata strain SMH1153 & FJ968953 & & \\
\hline Bertia multiseptata strain SMH3127 & FJ968952 & & \\
\hline Bertia ngongensis EA GKM1239 from TYPE material & NG058634 & & \\
\hline Bertia ngongensis strain GKM1239 & FJ968954 & & \\
\hline Bertia orbis strain GKM1259 & FJ968959 & & \\
\hline Bertia orbis strain GKM1271 & FJ968955 & & FJ969009 \\
\hline Bertia orbis strain SMH4035 & FJ968960 & & \\
\hline Bertia orbis strain SMH4557 & GQ184146 & & \\
\hline Bertia orbis USJ SMH4557 from TYPE material & NG058636 & & \\
\hline Bertia sinensis strain $\mathrm{SMH} 4034$ & FJ968961 & & \\
\hline Bertia triseptata F SMH1525 from TYPE material & NG058635 & & \\
\hline Bertia triseptata strain SMH1525 & FJ968957 & & \\
\hline Bertia triseptata strain SMH4379 & FJ968956 & & \\
\hline Bertia tropicalis F SMH1707 from TYPE material & NG058626 & & \\
\hline Bertia tropicalis strain SMH3132 & FJ968962 & & \\
\hline Bertia tropicalis strain SMH4046 & FJ968963 & & \\
\hline Bertia tropicalis voucher SMH1707 & AY695262 & & \\
\hline Bertia tropicalis voucher SMH3513 & AY695263 & & \\
\hline Biciliospora velutina strain GKM1268 & FJ968964 & FJ968932 & FJ969018 \\
\hline Chaetosphaerella fusca strain ANM53 & FJ968965 & & \\
\hline Chaetosphaerella fusca strain ANM79 & FJ968966 & & \\
\hline Chaetosphaerella fusca strain GKML124N & FJ968967 & & FJ969002 \\
\hline Chaetosphaerella phaeostroma & AY346274 & AY780172 & \\
\hline Chaetosphaerella phaeostroma strain SMH4585 & & & FJ969003 \\
\hline Chaetosphaerella phaeostroma voucher SMH4257 & AY695264 & FJ968940 & FJ969004 \\
\hline Coronophora myricoides IFRD 9201 from TYPE material & NG058972 & & \\
\hline
\end{tabular}


Cuadro 2. Continuación.

\begin{tabular}{|c|c|c|c|}
\hline \multirow{2}{*}{ Especie $^{1 /(\text { origen) }}$} & \multicolumn{3}{|c|}{ Números de acceso de GenBank } \\
\hline & $28 S$ & $r p b 2$ & tef1 $\alpha$ \\
\hline Coronophora myricoides strain IFRD 9201 & KX856174 & & \\
\hline Coronophorella chaetomioides strain GKM1099 & FJ968969 & FJ968922 & FJ969034 \\
\hline Coronophora gregaria strain ANM1555 & & FJ968938 & FJ969007 \\
\hline Crassochaeta nigrita voucher SMH1667 & AY695265 & & \\
\hline Crassochaeta nigrita voucher SMH2931 & AY695266 & & \\
\hline Cryptosphaerella celata EA GKM1231 from TYPE material & NG058772 & & \\
\hline Cryptosphaerella celata strain GKM1231 & FJ968975 & FJ968929 & FJ969035 \\
\hline Cryptosphaerella costaricensis F MO2111 from TYPE material & NG058769 & & \\
\hline Cryptosphaerella costaricensis strain M02111 & FJ968971 & & FJ969028 \\
\hline Cryptosphaerella cylindriformis EA GKM434N from TYPE material & NG058770 & & \\
\hline Cryptosphaerella cylindriformis strain GKM1042 & FJ968973 & FJ968918 & FJ969032 \\
\hline Cryptosphaerella cylindriformis strain GKM1075 & & FJ968920 & FJ969030 \\
\hline Cryptosphaerella cylindriformis strain GKM1187 & GQ217531 & FJ968925 & FJ969033 \\
\hline Cryptosphaerella cylindriformis strain GKM434N & FJ968972 & FJ968934 & FJ969031 \\
\hline Cryptosphaerella elliptica F SMH4722 from TYPE material & NG058771 & & \\
\hline Cryptosphaerella elliptica strain SMH4722 & FJ968974 & FJ968944 & FJ969029 \\
\hline Cryptosphaerella globosa strain $396 \mathrm{~N}$ & FJ968976 & & \\
\hline Cryptosphaerella globosa strain GKM414N & & & FJ969037 \\
\hline Cryptosphaerella globosa strain GKM437N & & & FJ969038 \\
\hline Cryptosphaerella globosa strain GKM469N & FJ968977 & FJ968935 & \\
\hline Cryptosphaerella globosa strain GKM471N & & & FJ969036 \\
\hline Cryptosphaerella malindensis EA GKM1150 from TYPE material & NG058768 & & \\
\hline Cryptosphaerella malindensis strain GKM1150 & FJ968970 & FJ968923 & FJ969027 \\
\hline Euacanthe foveolata strain GKM1221 & FJ968978 & FJ968927 & FJ969026 \\
\hline Euacanthe foveolata voucher SMH4408 & AY695267 & & \\
\hline Euacanthe renispora S. Chacón & MW349938 & MW349939 & MW349940 \\
\hline Fracchiaea broomeana strain SMH347 & FJ968979 & & \\
\hline Fracchiaea broomeana strain GKM1071 & & FJ968919 & FJ969040 \\
\hline Fracchiaea broomeana strain SMH347 & & & FJ969041 \\
\hline Fracchiaea broomeana voucher SMH2809 & AY695268 & FJ968942 & FJ969039 \\
\hline Fracchiaea lunata strain GKM1089 & & FJ968921 & \\
\hline Fracchiaea lunata strain GKM1250 & & & FJ969005 \\
\hline Gaillardiella pezizoides strain GKM1144 & FJ968980 & & \\
\hline Gaillardiella pezizoides strain GKM1245 & FJ968981 & & FJ969006 \\
\hline Nectria cinnabarina strain GJS 89107 & & & AF543785 \\
\hline Nectria cinnabarina strain GJS 91111 & & AF545567 & \\
\hline Neofracchiaea callista voucher SMH2689 & AY695269 & FJ968941 & FJ969020 \\
\hline Neotrotteria pulchella strain GKM1255 & FJ968982 & & \\
\hline Nitschkia calyculus strain SMH918 & FJ968983 & & \\
\hline Nitschkia grevillei & AY346294 & & \\
\hline Nitschkia menicoidea voucher SMH1523 & AY695270 & & \\
\hline Nitschkia meniscoidea F SMH1523 from TYPE material & NG060247 & & \\
\hline
\end{tabular}


Cuadro 2. Continuación.

\begin{tabular}{|c|c|c|c|}
\hline \multirow{2}{*}{ Especie $^{1 /(\text { origen) }}$} & \multicolumn{3}{|c|}{ Números de acceso de GenBank } \\
\hline & $28 S$ & $r p b 2$ & tef $1 \alpha$ \\
\hline Nitschkia pezizoidea voucher SMH4409 & AY695271 & & \\
\hline Nitschkia tetraspora strain GKML148N & FJ968987 & FJ968936 & FJ969011 \\
\hline Nitschkia tetraspora strain GKML213N & FJ968985 & & \\
\hline Nitschkia tetraspora strain SMH2469 2 & FJ968986 & & \\
\hline Nitschkia tetraspora strain SMH4787 & FJ968984 & & FJ969010 \\
\hline Parasympodiella elongata culture CBS 124768 & GQ303311 & & \\
\hline Parasympodiella elongata culture CBS 52293 & GQ303314 & & \\
\hline Parasympodiella elongata culture CPC 13288 & GQ303312 & & \\
\hline Parasympodiella elongata culture CPC 13498 & GQ303313 & & \\
\hline Parasympodiella elongata from TYPE material & NG057829 & & \\
\hline Parasympodiella elongata strain CBS 52293 & MH874088 & & \\
\hline Parasympodiella eucalypti culture CBS 124767 & GQ303315 & & \\
\hline Parasympodiella eucalypti from TYPE material & NG057830 & & \\
\hline Parasympodiella lauri CBS 138108 from TYPE material & NG058461 & & \\
\hline Parasympodiella lauri strain FMR 13132 & KY853518 & & \\
\hline Parasympodiella laxa culture CBS 102698 & GQ303316 & & \\
\hline Parasympodiella longispora strain CBS 54484 & MH873476 & & \\
\hline Pseudocatenomycopsis rothmanniae strain CPC 22733 & KF777237 & & \\
\hline Scortechinia acanthostroma strain GKML163N & FJ968991 & & FJ969015 \\
\hline Scortechinia acanthostroma strain SMH1143 & FJ968988 & FJ968948 & FJ969012 \\
\hline Scortechinia acanthostroma strain SMH1164 & FJ968989 & FJ968924 & FJ969014 \\
\hline Scortechinia acanthostroma strain SMH5313 & FJ968990 & & FJ969013 \\
\hline Scortechinia conferta voucher SMH2648 & AY695272 & & \\
\hline Scortechinia diminuspora F SMH4763 from TYPE material & NG059922 & & \\
\hline Scortechinia diminuspora strain SMH4763 & FJ968992 & & \\
\hline Scortechiniella similis strain SMH2006 & FJ968994 & FJ968945 & FJ969019 \\
\hline Scortechiniellopsis leonensis strain GKM1269 & FJ968993 & FJ968933 & FJ969021 \\
\hline Spinulosphaeria nuda SMH 1952 from TYPE material & NG059923 & & \\
\hline Spinulosphaeria nuda strain SMH1952 & FJ968995 & & \\
\hline Tympanopsis confertula strain GKM1242 & FJ968997 & FJ968930 & FJ969023 \\
\hline Tympanopsis confertula strain SMH1567 & FJ969001 & FJ968939 & FJ969025 \\
\hline Tympanopsis confertula strain SMH4841 & FJ968998 & FJ968946 & FJ969024 \\
\hline Tympanopsis confertula strain SMH2648 & & & FJ969022 \\
\hline Tympanopsis uniseriata strain GKM1203 & FJ968999 & FJ968926 & FJ969016 \\
\hline Tympanopsis uniseriata strain GKM1228 & FJ969000 & FJ968928 & FJ969017 \\
\hline Nectria cinnabarina strain GJS 89107 & & & AF543785 \\
\hline Nectria cinnabarina strain GJS 91111 & & AF545567 & \\
\hline Nectriopsis violacea & AF193242 & & \\
\hline
\end{tabular}




\section{Análisis filogenéticos}

Los análisis se realizaron con inferencia filogenética bayesiana (BPI) usando MrBayes v. 3.1.2 (Huelsenbeck y Ronquist, 2001; Ronquist y Huelsenbeck, 2003; Altekar et al., 2004). El modelo de sustitución se determinó con PartitionFinder 2 (Lanfear et al., 2017) para las tres matrices. Se corrieron cuatro cadenas de Markov (MCMC) independientes con dos millones de generaciones y $25 \%$ de "burn-in" cada 100 generaciones antes de calcular el árbol de consenso de mayoría y las probabilidades posteriores (PP) para los clados. Para enraizar el árbol se usaron especies de Hypocreales de acuerdo con Mugambi y Huhndorf (2010).

El apoyo estadístico de los nodos se determinó mediante un análisis de jackknife (JK) en PAUP v. 4 (Swofford, 2002) ejecutando 1000 réplicas con adición simple de secuencias, rearreglo de ramas TBR y $35 \%$ de caracteres eliminados. Adicionalmente, se realizó un "fast bootstrap" (BS) con 1000 réplicas y 10 búsquedas por réplica (Stamatakis, 2006; Boc et al., 2012) con el algoritmo "rapid hillclimbing", usando RAxML enTrex-online (http://www.trex. uqam.ca/index.php?action=raxml). Los árboles filogenéticos se dibujaron con FigTree v. 1.4 (Rambaut, 2014).

\section{Resultados}

Tres de los cuatro ejemplares de la especie nueva (Euacanthe renispora) estaban contaminados con Aspergillus Micheli., por lo que solo fue posible generar secuencias para el ejemplar Tapia 2797 (XAL). La comparación con blastn indicó que la especie con mayor identidad fue Euacanthe foveolata (= Acanthonitschkea foveolata) del orden Coronophorales, con únicamente cuatro secuencias disponibles en GenBank; dos para el $28 \mathrm{~S}$ y una para el $r p b 2$ y tef $1 \alpha$, respectivamente. Para el orden existen solo 208 al 6 de noviembre del 2020, las que se usaron para conocer la posición de Euacanthe renispora dentro del orden. De las 208 secuencias, se seleccionaron los genes que tenían mayor representatividad de especies y se eliminaron las de taxones no identificados. Después de la alineación, la matriz del 285 consistió en 99 terminales y 947 caracteres; la del rpb2 en 32 terminales y 797 caracteres y la del tef1 $\alpha$ en 44 terminales y 671 caracteres. El modelo de evolución de las secuencias para las tres matrices fue GTR (rates=invgamma, nst=6).
Los análisis filogenéticos con las matrices de los genes $28 \mathrm{~S}$ y rpb2 mostraron que Euacanthe renispora forma un grupo monofilético con E. foveolata con valores de apoyo altos (Figs. 2, 3). Sin embargo, el análisis con la matriz del gen tef1 $\alpha$ no agrupó a estas dos especies. Se observó que, en general, el tef1 $\alpha$ tiene menor resolución filogenética que el $28 \mathrm{~S}$ y el rpb2 (Fig. 3), pero evidenció que E. renispora es diferente al resto de las especies en ese clado, incluyendo un ejemplar de E. foveolata (Fig. 4). Adicionalmente, las cinco familias reconocidas de los Coronophorales (Mugambi y Huhndorf, 2010) se recuperaron monofiléticas en todos los análisis. Las excepciones fueron Nitschkia pezizoidea (Pat.) Kuntze (AY695271), que resultó parafilética, al igual que Fracchiaea broomeana (Berk.) Petch (AY695268, FJ968979), que se asocia a la familia Nitschkiaceae y Spinulosphaeria nuda Mugambi \& Huhndorf (FJ968995, NG 059923), que se ha agrupado en la familia Bertiaceae (Subramanian y Sekar, 1990).

\section{Taxonomía}

Euacanthe renispora S. Chacón, sp. nov. Figs. 5-7. MycoBank No.: MB 838214. TIPO: MÉXICO. Veracruz, municipio Xalapa, Parque ecológico "Cerro Macuiltépetl”, 1520 m, $19^{\circ} 32^{\prime} 54^{\prime \prime} \mathrm{N}, 96^{\circ} 55^{\prime} 09^{\prime \prime} \mathrm{O}$, sobre ramas de troncos caídos. 17.III.2013, F. Tapia 2797 (holotipo: XAL!).

Euacanthe renispora is closely related to Euacanthe foveolata (= Acanthonitschkea foveolata), but with smaller ascospores which are strictly reniform. Ascomata turbinate, collabent when dry, non-ostiolate, gregarious, seated on a dense subiculum developed on the surface of the bark, quellkörper bodies present. Asci 20-35 × 10-12 $\mu \mathrm{m}$. Ascospores often reniform to occasionally obovate, hyaline, smooth, (4-)4.5-6(-6.5) × (3-)3.5-4 $\mu \mathrm{m}$.

Ascoma carente de ostiolo, turbinado, colapsado cuando seco, gregario, asentado sobre un subículo denso, desarrollado sobre la superficie de la corteza, 500-600 $\mu \mathrm{m}$ de altura, 400-500 $\mu \mathrm{m}$ de ancho, superficie negra con abundantes setas; peridio 70-80 $\mu \mathrm{m}$ de ancho, constituido por células alargadas pseudoparenquimatosas formando cadenas, externamente de color oscuro a color marrón a 


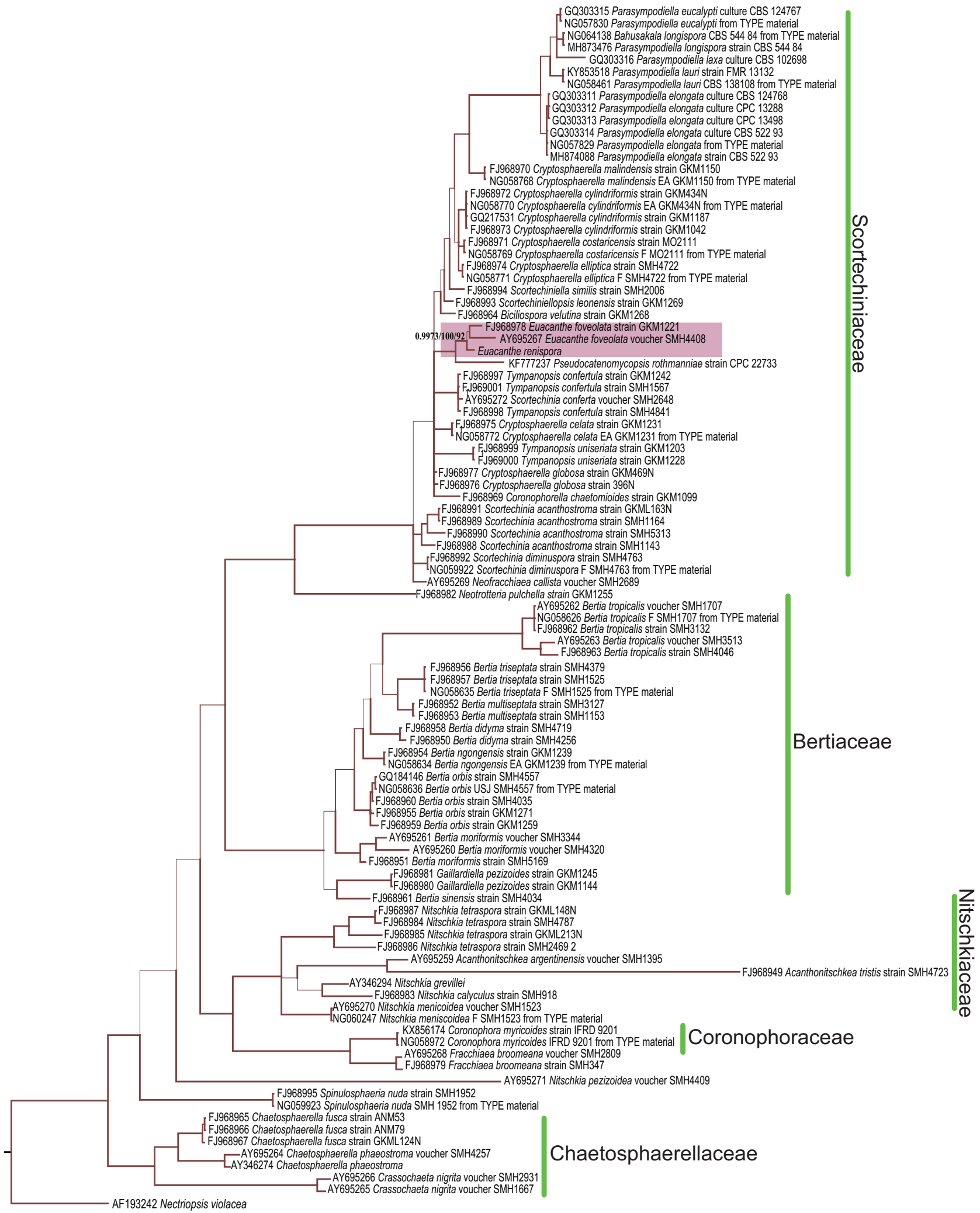

Figura 2: Filograma del árbol de consenso de mayoría bayesiana de 50\%, resultado del análisis de las secuencias de una región del 285 . En el cuadro rosa se muestra la posición de Euacanthe renispora S. Chacón con los valores de apoyo (PP/JK/BS). El grosor de las ramas indica el nivel de apoyo de las PP. A la derecha del nombre de la especie el número de acceso a GenBank, a la izquierda su origen. CBS: Central Bureau of Fungal Cultures; CPC: Culture collection of Pedro Crous; GKM: George K. Mugambi; IFRD: International Fungal Research \& Development Centre; FMR: Facultat de Medicina i Ciències de la Salut; SMH: Sabine M. Huhndorf; ANM: Andrew N. Miller; F: Field Museum of Natural History; EA: National Museum of Kenya; MO: Missouri Botanical Garden. 


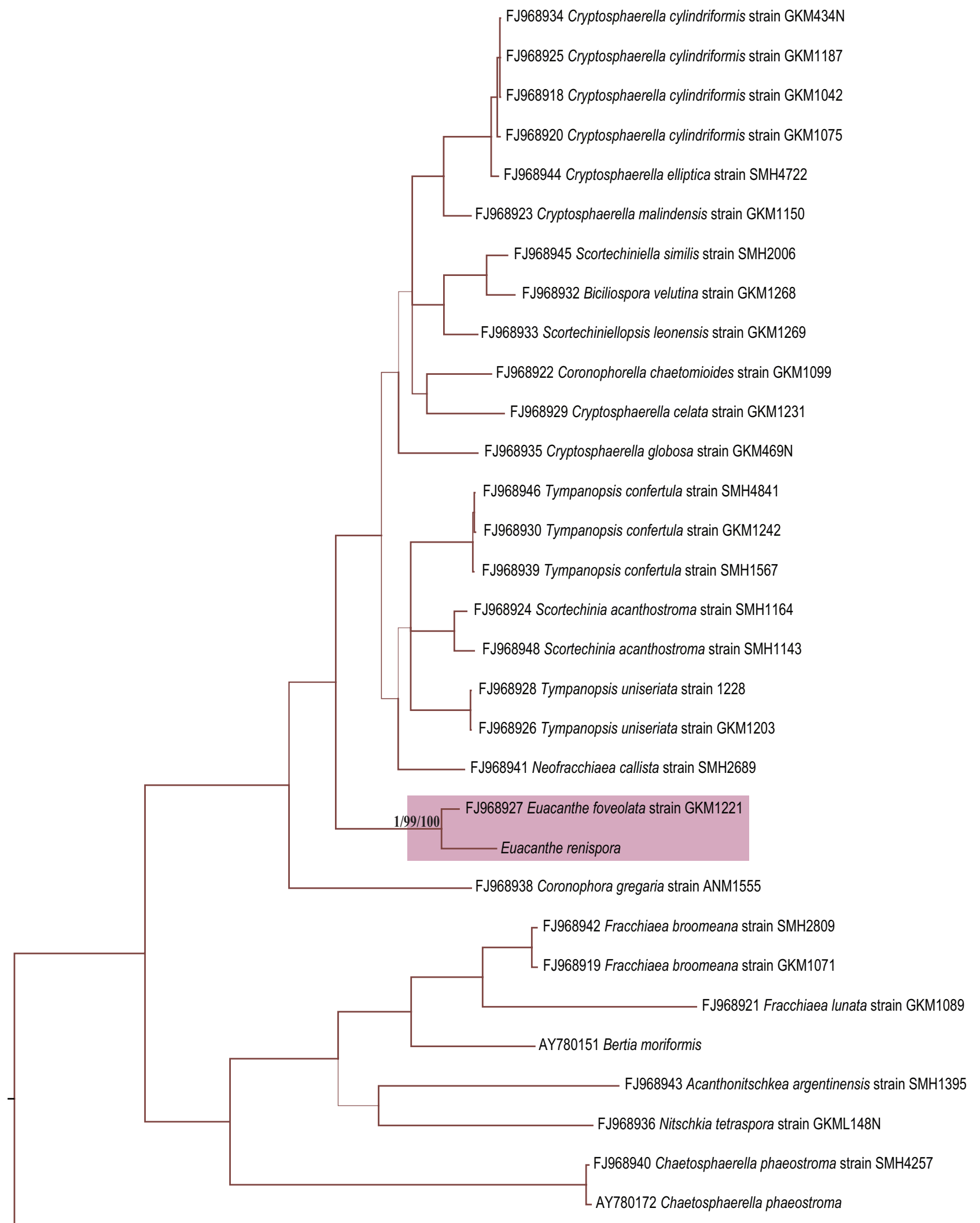

AF545567 Nectria cinnabarina strain GJS 91111

Figura 3: Filograma del árbol de consenso de mayoría bayesiana de $50 \%$ resultado del análisis de las secuencias de una región del rpb2. En el cuadro rosa se muestra la posición de Euacanthe renispora S. Chacón con los valores de apoyo (PP/JK/BS). El grosor de las ramas indica el nivel de apoyo de las PP. A la derecha del nombre de la especie el número de acceso a GenBank, a la izquierda su origen. GKM: George K. Mugambi; SMH: Sabine M. Huhndorf; ANM: Andrew N. Miller; GJS: Gary J. Samuels. 


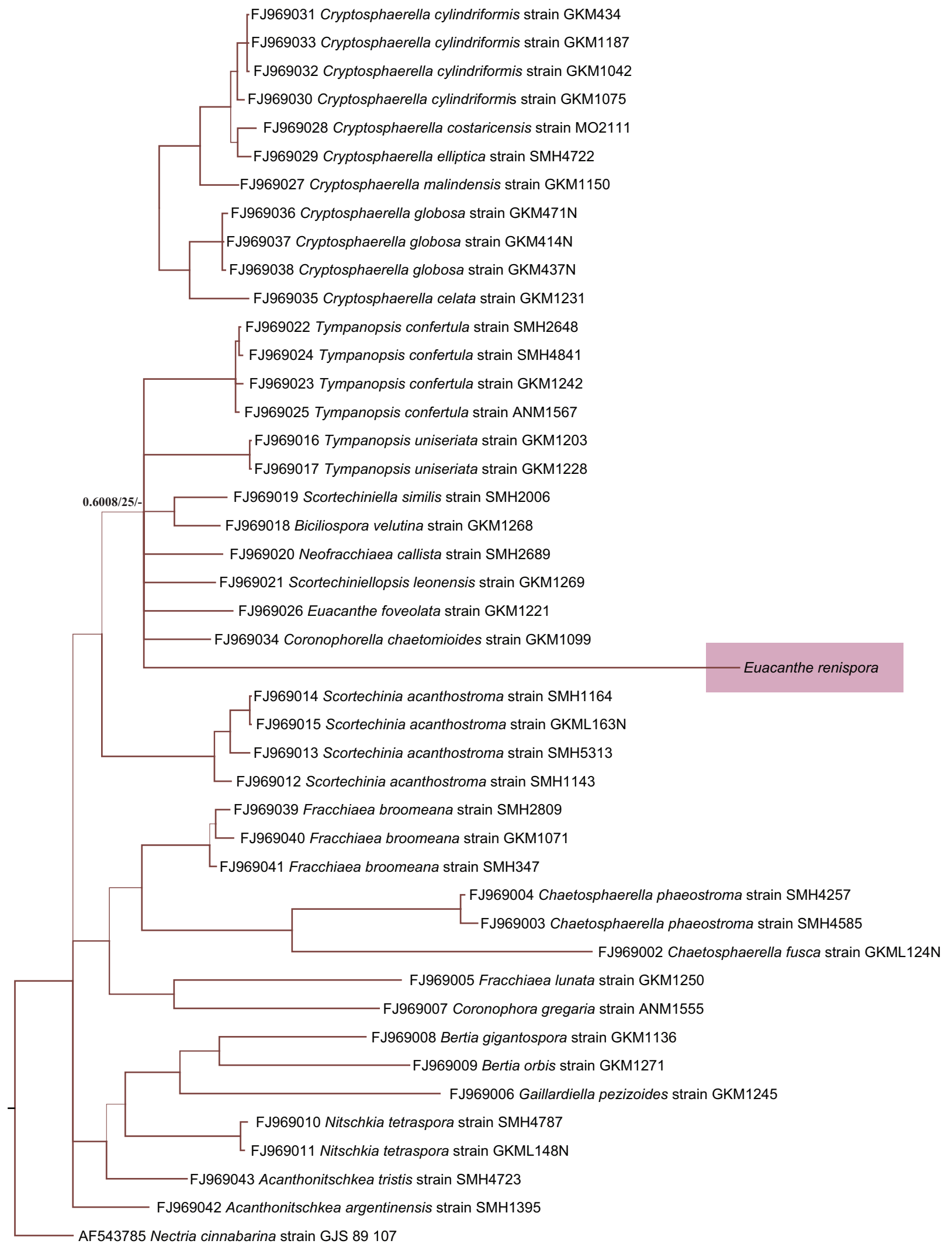

0.08

Figura 4: Filograma del árbol de consenso de mayoría bayesiana de $50 \%$ resultado del análisis de las secuencias de una región del tef1 $\alpha$. En el cuadro rosa se muestra la posición de Euacanthe renispora S. Chacón con los valores de apoyo (PP/JK/BS). El grosor de las ramas indica el nivel de apoyo de las PP. A la derecha del nombre de la especie el número de acceso a GenBank, a la izquierda su origen. GKM: George K. Mugambi; SMH: Sabine M. Huhndorf; ANM: Andrew N. Miller; MO: Missouri Botanical Garden; GJS: Gary J. Samuels. 
marrón pálido al interior, 1-3 poros de Munk; hifas del subículo ramificadas, septadas, 5-8 $\mu \mathrm{m}$ diámetro, color café pálido; setas presentes en el ascoma y subículo 175-350 × 10-20 $\mu \mathrm{m}$, marrón rojizo oscuro, anchas en la base, adelgazándose hacia la punta; quellkörper presentes; ascas 20-35 × 10-12 $\mu \mathrm{m}$, claviformes con un pedúnculo corto, pared delgada, octosporadas, finalmente evanescentes; ascosporas reniformes a ocasionalmente aovadas, hialinas, lisas, (4-)4.5-6(-6.5) × (3-)3.5-4 $\mu \mathrm{m}$; paráfisis no observadas.
Notas taxonómicas: Euacanthe renispora es parecida a E. foveolata, citado por Nannfeldt (1975) como Acanthonitschkea foveolata; sin embargo, esta última se diferencia de la primera porque presenta esporas ovoides o elipsoides subfusiformes, casi rectas y un poco más grandes $(5-8 \times 2-3 \mu \mathrm{m})$. Subramanian y Sekar (1990) citaron para E. foveolata esporas más pequeñas de 5-6.5 × 3.0-3.5 $\mu \mathrm{m}$, elípticas a reniformes, características que lo asemejan al material mexicano. Sin embargo, debido a que el nombre válido para Euacanthe foveolata es Akanthonitschkea
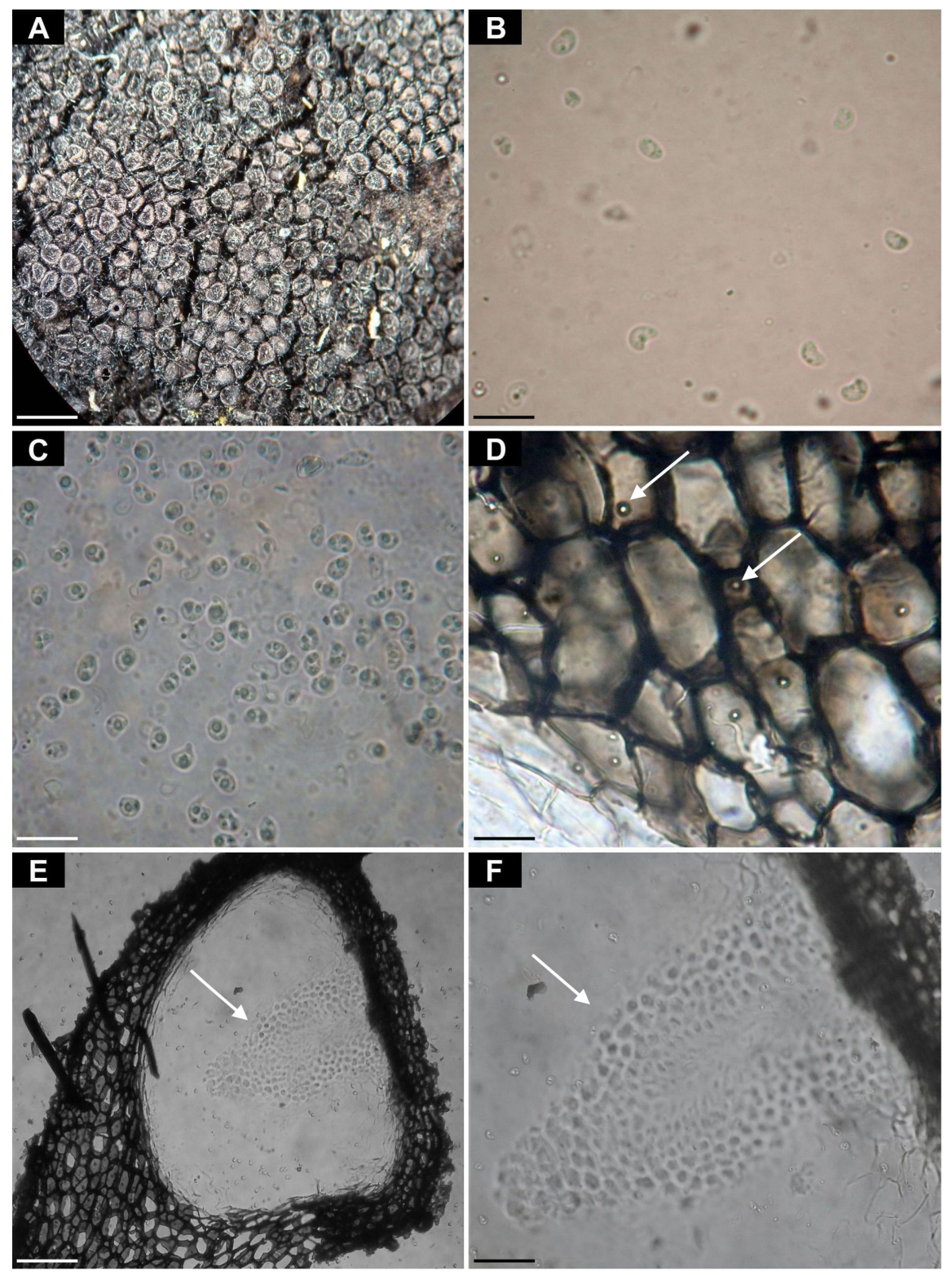

Figura 5: Euacanthe renispora S. Chacón. A. ascomas; B, C. esporas reniformes; D. células de la pared del ascoma, las flechas muestran los poros de Munk; E, F. sección longitudinal de un ascoma, las flechas muestran los cuerpos quellkörper. Escala, $A=1.5 \mathrm{~mm} ; \mathrm{B}, \mathrm{C}=14 \mu \mathrm{m} ; \mathrm{D}=10 \mu \mathrm{m} ; \mathrm{E}=90 \mu \mathrm{m} ; \mathrm{F}=60$ $\mu \mathrm{m}$. Edición de imagen por Manuel Díaz. 

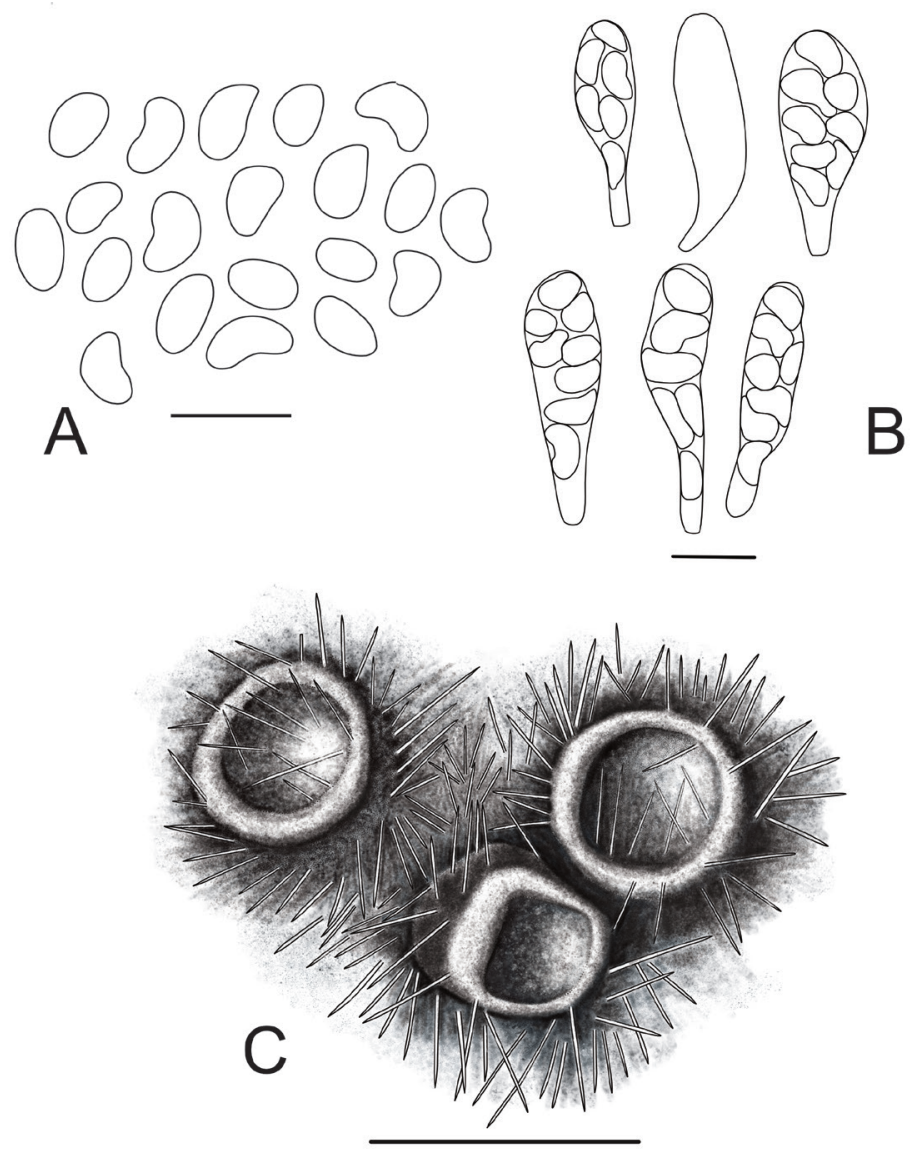

Figura 6: Euacanthe renispora S. Chacón. A. esporas; B. ascas con ascosporas; C. ascomas. Escala, $A=7 \mu \mathrm{m} ; B=9 \mu \mathrm{m} ; C=0.75 \mu \mathrm{mm}$. Dibujo por Manuel Escamilla.

foveolata, la ausencia de cuerpos quellkörper en las especies de Acanthonitschkea las separan. Por otro lado, al revisar el material tipo de Acanthonitschkea amarkantakensis Patel, A.K. Pandey \& R.C. Rajak, citada de India por Patel et al. (2003), se observó la presencia de cuerpos quellkörper, característica típica de Euacanthe y de otros géneros de Coronophorales, pero no de Acanthonitschkea (Subramanian y Sekar, 1990; Mugambi y Huhndorf, 2010).

Etimología: el nombre específico renispora hace referencia a las esporas de forma reniforme

Ejemplares examinados: MÉXICO. Veracruz, municipio Coatepec, Zoncuantla, en el jardín de una casa, $19^{\circ} 29^{\prime} 59^{\prime \prime} \mathrm{N}, 96^{\circ} 56^{\prime} 38^{\prime \prime} \mathrm{O}, 1270 \mathrm{~m}$, corteza de ramas caídas, 19.I.1999, G. Guzmán 32780 (XAL). Municipio Xalapa, jardín de una casa, $19^{\circ} 31^{\prime} 17^{\prime \prime} \mathrm{N}, 96^{\circ} 56^{\prime} 19^{\prime \prime} \mathrm{O}$, sobre corteza de ramas caídas, 08.X.1983, G. Guzmán 24105 (XAL); Jardín

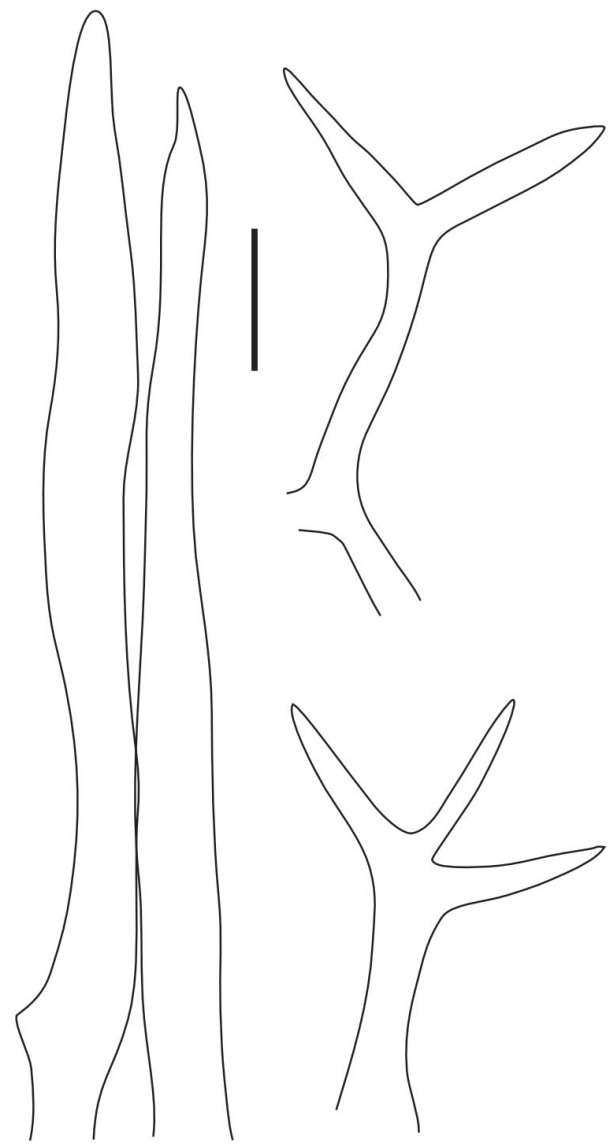

Figura 7: Euacanthe renispora S. Chacón. Setas. Barra=40 $\mu \mathrm{m}$. Dibujo por Manuel Escamilla.

Botánico Francisco Javier Clavijero, km 2.5 antigua carretera Xalapa - Coatepec, $19^{\circ} 29^{\prime} 00^{\prime \prime} \mathrm{N}, 97^{\circ} 09^{\prime} 00^{\prime \prime O}, 1300$ m, sobre corteza de ramas caídas, 07.IX.1995, S. Chacón 4935 (XAL).

Ejemplar examinado de Acanthonitschkea amarkantakensis: INDIA. Amarkantak, Madhya Pradesh, Shahdol, III.1991, sobre Psidium guajava L., leg. U.S. Patel, IMI 354054 (holotipo: K!).

\section{Discusión y Conclusiones}

Los estudios sobre hongos, y en particular de los ascomicetos, procedentes de áreas verdes urbanas (parques y jardines) de Xalapa son muy escasos; no obstante, en contribuciones recientes se reconocieron algunos nuevos registros y especies nuevas (Tapia et al., 2017; Chacón et al., 2018(2019); Chacón-Zapata, 2019; Chacón y González, 2019). 
Hasta ahora, el género Euacanthe era considerado monotípico. Sin embargo, con la inclusión de E. renispora procedente de distintas localidades de Xalapa y alrededores, se sugiere una mayor distribución y abundancia de las especies en el bosque mesófilo de montaña de la región. Se observó variación en el tamaño y forma de las esporas en los cuatro ejemplares colectados. Los ejemplares Chacón 4935 (XAL) y Guzmán 32767 (XAL), 32780 (XAL) presentan esporas de 4.5-6(-6.5) × (3-)3.5-4 $\mu \mathrm{m}$, ovoides, elipsoides o reniformes; mientras que en el ejemplar de Tapia 2797 (XAL) (Tipo) se encontraron esporas ligeramente más grandes, 5.5-7(-9) × 3.5-4 $\mu \mathrm{m}$, y regularmente reniformes. $A$ pesar de esto, todas las muestras mexicanas se incluyen como parte del material estudiado de Euacanthe renispora, constituyendo la primera especie de Euacanthe registrada en México y la segunda para el género. Sin embargo, para dilucidar la abundancia y diversidad de E. renispora en las áreas verdes urbanas y periurbanas de Xalapa, es necesario realizar nuevas recolecciones y hacer análisis adicionales. Particularmente porque, salvo para el ejemplar Tapia 2797 (XAL) (Tipo), de los tres ejemplares restantes no se lograron obtener secuencias puras, debido a que las secuencias de estas muestras resultaron estar contaminadas con Aspergillus sp.

La filogenia de los Coronophorales con las secuencias del 28S mostró algunas diferencias en la ubicación de los géneros a la obtenida por Mugambi y Huhndorf (2010), como la posición de las especies Nitschkia pezizoidea, Fracchiaea broomeana y Spinulosphaeria nuda. No obstante, Nitschkia G.H. Otth ex P. Karst. resultó en un clado monofilético junto con Acanthonitschkea en otro análisis, pero su relación no estuvo apoyada (Mugambi y Huhndorf, 2010). Por otro lado, el género Fracchiaea Sacc., aunque se ha asociado con la familia Nitschkiaceae, actualmente se considera polifilético; en nuestro análisis resultó formando un clado con dos ejemplares de la familia Coronophoraceae. Adicionalmente, la pertenencia del género Spinulosphaeria Sivan. dentro de los Coronophorales ha sido fuertemente debatida (Mugambi y Huhndorf, 2010). Por lo tanto, el análisis de estos taxa requiere un mayor escrutinio. Finalmente, debido a la presencia de cuerpos quellkörper en el material tipo de $A$. amarkantakensis, se sugiere a futuro transferir esta especie al género Euacanthe.

\section{Contribución de autores}

SCH y DG generaron y diseñaron el estudio, y participaron en la adquisición de los datos para el mismo. $\mathrm{SCH}$ realizó la revisión de ejemplares de herbario, la recolección de material fresco, la determinación de la especie y la toma de fotografías. DG contribuyó con los análisis filogenéticos y la elaboración de cladogramas. Ambos autores contribuyeron a la discusión, revisión y aprobación del manuscrito final.

\section{Financiamiento}

Este estudio fue financiado, en parte, por el Instituto de Ecología, A.C., a través del proyecto estratégico de la dirección general "Estudio integral 2013-2037 de la Biodiversidad del Jardín Botánico Francisco Javier Clavijero con énfasis en el Santuario del Bosque de Niebla", con el fin de vincular el conocimiento sobre la riqueza biológica/capital natural con desarrollos tecnológicos de alto valor agregado para la sociedad, generados en el Clúster Científico y Tecnológico BioMimic ${ }^{\circledR}$, por el proyecto 20035-30890 y con recursos propios.

\section{Agradecimientos}

Se agradece al Instituto de Ecología, A.C. las facilidades brindadas para la elaboración de este trabajo. A Elsa Utrera Barillas, Florencia Ramírez Guillén, Juan Lara Carmona y Fidel Tapia, se les reconoce por su apoyo en distintas actividades logísticas. A Manuel Díaz y Manuel Escamilla por la edición de imágenes y dibujos. Extendemos nuestro agradecimiento al revisor por sus comentarios y al editor por sus acertadas sugerencias para mejorar el manuscrito.

\section{Literatura citada}

Altekar, G., S. Dwarkadas, J. P. Huelsenbeck y F. Ronquist. 2004. Parallel Metropolis coupled Markov chain Monte Carlo for Bayesian phylogenetic inference. Bioinformatics 20(3): 407415. DOI: https://doi.org/10.1093/bioinformatics/btg427

Bandala, V. M. y L. Montoya. 2014. Galerella (Bolbitiaceae, Agaricales) sp. nov. found in an urban green area in Xalapa, Veracruz, Mexico. Mycotaxon 129(2): 421-427. DOI: https:// doi.org/10.5248/129.421

Boc, A., A. B. Diallo y V. Makarenkov. 2012. T-REX: a web server for inferring, validating and visualizing phylogenetic trees and 
networks. Nucleic Acids Research 40(W1): W573-579. DOI: https://doi.org/10.1093/nar/gks485

Capitanachi, C., E. Utrera y C. B. Smith. 2004. El bosque urbano de Xalapa, Veracruz (libro electrónico). Instituto de Ecología A.C., Universidad Veracruzana, Sistema de Investigación del Golfo de México (Consejo Nacional de Ciencia y Tecnología). Xalapa, México. 717 pp.

Chacón, S. y D. González. 2019. A new species of penzigioid Xylaria (Xylariaceae) from the cloud forest in eastern Mexico revealed through morphological and phylogenetic analyses. Botany 97(7): 381-389. DOI: https://doi.org/10.1139/cjb2019-0043

Chacón, S., G. Guzmán, L. Montoya y V. M. Bandala. 1995. Guía ilustrada de los hongos del Jardín Botánico Francisco J. Clavijero de Xalapa, Veracruz y áreas circunvecinas. Instituto de Ecología, A.C. Xalapa, México. 142 pp.

Chacón, S., F. Tapia y M. Esqueda. 2014. New records of Dothideomycetes from Mexico. Mycotaxon 128: 145-157. DOI: https://doi.org/10.5248/128.145

Chacón, S., E. Utrera-Barillas y M. A. García-Martínez. 2018(2019). Temporal shifts in a Xylaria assemblage (Ascomycota, Xylariaceae) resulting from management activities in a protected cloud forest. Acta Botanica Mexicana 126: e1378. DOI: https://doi.org/10.21829/abm126.2019.1378

Chacón-Zapata, S. 2019. Nuevos registros de Pleosporales (Ascomycota) para México. Revista Mexicana de Biodiversidad 90: e902493. DOI: https://doi.org/10.22201/ ib.20078706e.2019.90.2493

Chacón-Zapata, S. y F. Tapia-Padilla. 2013. Algunas especies del género Byssosphaeria (Melanommataceae, Pleosporales) de Veracruz, México. Revista Mexicana de Biodiversidad 84: 739-745. DOI: https://doi.org/10.7550/rmb.32985

Hall, T. A. 1999. BioEdit: a user-friendly biological sequence alignment analysis program for Windows 95/98/NT. Nucleic Acids Symposium Series 41: 95-98.

Heredia, G., R. M. Arias y M. Reyes. 2000. Contribución al conocimiento de los hongos Hyphomycetes de México. Acta Botanica Mexicana 51: 39-51. DOI: https://doi. org/10.21829/abm51.2000.849

Huelsenbeck, J. P. y F. Ronquist. 2001. MRBAYES: Bayesian inference of phylogenetic trees. Bioinformatics 17(8): 754-755. DOI: https://doi.org/10.1093/ bioinformatics/17.8.754
Huhndorf, S. M., A. N. Miller y F. A. Fernández. 2004. Molecular systematics of the Coronophorales and new species of Bertia, Lasiobertia and Nitschkia. Mycological Research 108(12): 1384-1398. DOI: https://doi.org/10.1017/ S0953756204001273

Hyde, K. D., C. Norphanphoun, S. S. N. Maharachchikumbura, D. J. Bhat, E. B. G. Jones, D. Bundhun, Y. J. Chen, D. F. Bao, S. Boonmee, M. S. Calabon, N. Chaiwan, K. W. T. Chethana, D. Q. Dai, M. C. Dayarathne, B. Devadatha, A. J. Dissanayake, L. S. Dissanayake, M. Doilom, W. Dong, X. L. Fan, I. D. Goonasekara, S. Hongsanan, S. K. Huang, R. S. Jayawardena, R. Jeewon, A. Karunarathna, S. Konta, V. Kumar, C. G. Lin, J. K. Liu, N. G. Liu, J. Luangsa-ard, S. Lumyong, Z. L. Luo, D. S. Marasinghe, E. H. C. McKenzie, A. G. T. Niego, M. Niranjan, R. H. Perera, C. Phukhamsakda, A. R. Rathnayaka, M. C. Samarakoon, S. M. B. C. Samarakoon, V. V. Sarma, I. C. Senanayake, Q. J. Shang, M. Stadler, S. Tibpromma, D. N. Wanasinghe, D. P. Wei, N. N. Wijayawardene, Y. P. Xiao, J. Yang, X. Y. Zeng, S. N. Zhang y M. M. Xiang. 2020. Refined families of Sordariomycetes. Mycosphere 11(1): 305-1059. DOI: https://doi.org/10.5943/mycosphere/11/1/7

Index Fungorum. 2021. The global fungal nomenclator. http:// www.indexfungorum.org/names/Names.asp (consultado febrero de 2021).

Kirk, P. M., P. F. Cannon, D. W. Minter y J. A. Stalpers. 2008. Ainsworth and Bisby's dictionary of the Fungi, 10th ed. CAB International. Wallingford, UK. 784 pp.

Lanfear, R., P. B. Frandsen, A. M. Wright, T. Senfeld y B. Calcott. 2017. PartitionFinder 2: new methods for selecting partitioned models of evolution for molecular and morphological phylogenetic analyses. Molecular Biology and Evolution 34(3): 772-773. DOI: https://doi.org/10.1093/ $\mathrm{molbev/msw260}$

Liu, Y. J., S. Whelen y B. D. Hall. 1999. Phylogenetic relationships among ascomycetes: evidence from an RNA polymerase II subunit. Molecular Biology and Evolution 16(12): 17991808. DOI: https://doi.org/10.1093/oxfordjournals.molbev. a026092

MacGregor-Fors, I., F. Escobar, R. Rueda, S. Avendaño-Reyes, M. L. Baena, V. M. Bandala, S. Chacón-Zapata, A. Guillén-Servent, F. González-García, F. Lorea-Hernández, E. Montes de Oca, L. Montoya, E. Pineda, L. Ramírez-Restrepo, E. Rivera-García y E. Utrera-Barrillas. 2016. City “Green" Contributions: The 
Role of Urban Greenspaces as Reservoirs for Biodiversity. Forests 7(7): 146. DOI: https://doi.org/10.3390/f7070146

Maharachchikumbura, S. S. N., K. D. Hyde, E. B. G. Jones, E. H. C. McKenzie, J. D. Bhat, M. C. Dayarathne, S.-K. Huang, C. Norphanphoun, I. C. Senanayake, R. H. Perera, Q.-J. Shang, Y. Xiao, M. J. D’souza, S. Hongsanan, R. S. Jayawardena, D. A. Daranagama, S. Konta, I. D. Goonasekara, W.-Y. Zhuang, R. Jeewon, A. J. L. Phillips, M. A. Abdel-Wahab, A. M. Al-Sadi, A. H. Bahkali, S. Boonmee, N. Boonyuen, R. Cheewangkoon, A. J. Dissanayake, J. Kang, Q.-R. Li, J. K. Liu, X. Z. Liu, Z.-Y. Liu, J. J. Luangsa-ard, K.-L. Pang, R. Phookamsak, I. Promputtha, S. Suetrong, M. Stadler, T. Wen y N. N. Wijayawardene. 2016. Families of Sordariomycetes. Fungal Diversity 79: 1-317. DOI: https://doi.org/10.1007/ s13225-016-0369-6

Medel, R. y F. Calonge. 2004. Aportación al conocimiento de los Discomycetes de México, con especial referencia al género Helvella. Boletín de la Sociedad Micológica de Madrid 28: 151-159.

Medel, R. y S. Chacón. 1988. Ascomycetes lignícolas de México, II. Algunos Pyrenomycetes y Discomycetes. Micología Neotropical Aplicada 1: 87-96.

Medel, R., G. Guzmán y R. Castillo. 2008. Las especies de Xylaria (Ascomycota, Xylariaceae) conocidas de Veracruz, México y discusión de nuevos registros. Revista Mexicana de Micología 28: 101-118.

Mugambi, G. K. y S. M. Huhndorf. 2010. Multigene phylogeny of the Coronophorales: morphology and new species in the order. Mycologia 102(1): 185-210. DOI: https://doi. org/10.3852/09-043

Muñiz-Castro, M. A., G. Williams-Linera y J. M. R. Benayas. 2006. Distance effect from cloud forest fragments on plant community structure in abandoned pastures in Veracruz, Mexico. Journal of Tropical Ecology 22(4): 431-440. DOI: https://doi.org/10.1017/S0266467406003221

Nannfeldt, J. A. 1975. Stray studies in the Coronophorales (Pyrenomycetes) 4-8. Svensk Botanisk Tidskrift 69: 289-335.

Patel, U. S., A. K. Pandey y R. C Rajak. 2003. Acanthonitschkea amarkantakensis sp. nov. from India. Journal of Mycology and Plant Pathology 33(2): 325-326.

Rambaut, A. 2014. FigTree v. 1.4: tree figure drawing tool. http:// tree.bio.ed.ac.uk/software/figtree/ (consultado febrero de 2021).
Raymundo, T., E. Escudero-Leyva, I. Ortega-López, D. CastroBustos, H. León-Avendaño y R. Valenzuela. 2014. Ascomicetos del bosque tropical caducifolio en el Parque Nacional Lagunas de Chacahua, Oaxaca, México. Boletín de la Sociedad Micológica de Madrid 38: 9-21.

Reeb, V., F. Lutzoni y C. Roux. 2004. Contribution of RPB2 to multilocus phylogenetic studies of the euascomycetes (Pezizomycotina, Fungi) with special emphasis on the lichen-forming Acarosporaceae and evolution of polyspory. Molecular Phylogenetics and Evolution 32(3): 1036-1060. DOI: https://doi.org/10.1016/j.ympev.2004.04.012

Robert, V., G. Stegehuis y J. Stalpers. 2005. The MycoBank engine and related databases. https://www.mycobank.org/ (consultado febrero de 2021).

Ronquist, F. y J. P. Huelsenbeck. 2003. MrBayes 3: Bayesian phylogenetic inference under mixed models. Bioinformatics 19(12): 1572-1574. DOI: https://doi.org/10.1093/ bioinformatics/btg180

San Martín González, F. 1996. Contribución al conocimiento de cinco géneros de la familia Nitschkiaceae (Hymenoascomycetes: Sordariales). Acta Botanica Mexicana 36: 43-52. DOI: https://doi.org/10.21829/abm36.1996.760

San Martín González, F. y P. A. Lavín. 1997. Los Ascomycetes Acanthonitschkia, Corynelia, Lopadostoma y Camarops en México. Acta Botanica Mexicana 41: 31-41. DOI: https:// doi.org/10.21829/abm41.1997.790

Stamatakis, A. 2006. RAxML-VI-HPC: maximum likelihood-based phylogenetic analyses with thousands of taxa and mixed models. Bioinformatics 22(21): 2688-2690. DOI: https://doi. org/10.1093/bioinformatics/bt|446

Subramanian, C. V. y G. Sekar. 1990. Coronophorales from India-a monograph. Kavaka 18: 19-90.

Sung, G.-H., J.-M. Sung, N. Hywel-Jones y J. Spatafora. 2007. A multi-gene phylogeny of Clavicipitaceae (Ascomycota, Fungi): Identification of localized incongruence using a combinational bootstrap approach. Molecular Phylogenetics and Evolution 44(3): 1204-1223. DOI: https:// doi.org/10.1016/j.ympev.2007.03.011

Swofford, D. L. 2002. PAUP*: Phylogenetic Analysis Using Parsimony (*and Other Methods). Version 4, Sinauer Associates. Sunderland, USA.

Tapia, F., Y.-M. Ju, S. ChacónyE. Utrera-Barillas. 2017. Five penzigioid Xylaria species from Veracruz (Mexico). Mycotaxon 132(1): 
19-27. DOI: https://doi.org/10.5248/132.19

Toledo-Aceves, T., J. G. García-Franco, G. Williams-Linera, K. MacMillan y C. Gallardo-Hernández. 2014. Significance of remnant cloud forest fragments as reservoirs of tree and epiphytic bromeliad diversity. Tropical Conservation Science 7(2): 230-243. DOI: http://doi. org/10.1177/194008291400700205

Vilgalys, R. y M. Hester. 1990. Rapid genetic identification and mapping of enzymatically amplified ribosomal DNA from several Cryptococcus species. Journal of Bacteriology 172(8): 4238-4246. DOI: http://doi.org/10.1128/jb.172.8.42384246.1990
Zolá, M. 1987. La vegetación de Xalapa, Veracruz. Instituto Nacional de Investigaciones sobre Recursos Bióticos (INIREB). Xalapa, México. 155 pp. 